ANASTOMOSIS OF BIADDER TO RECTUM. EXPERIMENTAL RESEARCH THEREON: A PRELIMINARY
REPORT. BY JACOB FRANK, M. D.

Surgeon to the St. Elizabeth and German Hospitals; Consulting Surgeon to the Jewish Orphan Home and Home for Aged Jews, Chicago;

Corresponding Member of the Sociedad Medica "Pedro Escobedo"

Member of the Pan-American Congress, International Congress, dmerican Medica
chICAGo.

In the spring of 1898 a series of experiments on the unilateral and bilateral implantation of the severed urilateral into the rectum was conducted after a special mothod of my own, with the object of relieving many of the grave pathologic conditions arising in the bladder, that are aggravated by the presence of urine, or in concenital malformations, as exstrophy, as well as the avoidance of a nephrectomy for neoplasms involving the ureters, or injuries to the ureters in laparotomies. The ultimate results of these were discouraging, although the operative technic was all that could have been wished for. From the knowledge and experience gained, and loeping in mind the numerous pathologic conditions to which the bladder is heir, the plan of anastomosing the bladder to the rectum seemed feasible and was carried out on fifteen dogs, with goor results. After looking orer all the arailable literature upon the subject of exstrophy of the bladder, etc., I find no one attempting this method, and therefore I think I may elaim originality for the same.

The operation consists of anastomosing the bladder to the rectum with my decalcified bone coupler, a description of which can be found in the Medical Recurd, Oct. 3, 1896, the Journat, June 19, 189\%, and in Medicine, January, $189 \%$. The technic is as follows: in a male dog the incision is made in the groin, and in a bitch in the median line. Generally the bladder is fom distended, and is emptied by squeezing it gently with the hand, when the urine escapes through the natural channel. The rectum is next picked up and freed of its contents, as in any intestinal operation. The bladder and the rectum are then brought forward and placed in position for anastomosis. Two or three interrupted Lembert sutures are now taken about half in inch below the lower ends of the incisions determined upon in the bladder and rectum, care being exercised in selecting them that the coupler, when it is inserted, will not encroach upon the ureteral openings in the bladder. A longitudinal incision is then made in the bladder large enough for the coupler selected, and a puckering string applied over and over the cut margin. The rectum is next opened in its long axis and a puckering string similarly applied. The suture should be taken so that the free ends lie uppermost, thus facilitating easy tying. The operator now slips the coupler into the bladder opening, at the same time gently spreading the collars apart, while an assistant makes one knot and draws down on the puckering string until the rubber tubing is felt; another knot is made and the ligature cut off short. The other half of the coupler is then slipped into the rectal opening and likewise tied and cut off. Several interrupted Lembert sutures are taken around the borders to make the work more secure. The operation is very simple and can be accomplished in ten or fifteen minutes.

of the fifteen $\operatorname{dogs}$ operated upon, ten recovered and five died. Post-mortems showed no septic conditions of ureters or kidneys. In the first two experiments the technic was not thoroughly understood, and a large amount of unnecessary work was done. Several of the dogs that rccovered were killed for pathologic and bacteriologic examination. Three are still living-the longest three months-and it is my intention to keep these somewhat longer and then kill them for the further study of the effects of the operation upon the ureters, kidneys and site of anastomosis. The dogs pass three or four watery stools a day through the rectum, and the male dogs hoist their legs in the act of micturition but without accomplishing it through the penis. The animals are playful and lively after recovery; and one not knowing an operation has been performed would have no suspicion aroused.

In the first six experiments a $5 / 8$ inch coupler was used, but later in large dogs a $7 / 8$ inch, and in smaller dogs a $3 / 4$ inch coupler was inserted. The small piece of rubber' tubing has never failed to pass away. Silk was used in all experiments. The following pathologic and bacteriologic reports of experiments 4 and 13 were made for me by Dr. Maxmilian Herzog:

Experiment 4.- Male dog, weight 22 pounds; operated on May 6, 1899, killed May 21, 1899 . At the post-mortem examination the following technic and inoculations were made: The ureters of both kidneys were ligated a short distance below their origin from the pelvis, and the kidney removed. A platinum loop previously heated was introduced through an opening-made under the usual aseptic conditions-into the pelvis of each kidney, and a blood-serum and glycerin-agar tube inoculated from each side. Of these four culture-media three remained permanently sterile. One blood-serum tube on the third day showed a moist, shiny, whitish growth which liquefied the culture soil. The growth consisted of very small bacilli, the character of which was not studied any further. They were not colon bacilli, and their appearance was probably due to contamination. At the site where the anastomosis was made the tissue appeared perfectly smooth and normal. No redness or swelling was noticeable to the naked eye. Microscopic sections made from this part, including both the bladder" and rectum, were stained by various methods.

In the rectum the following conditions were noted: The intestinal and bladder walls have completely united, and blend in such a manner that the two tissues form an acute angle of about 80 degrees, which projects into the bladder. The intestinal surface is lined by mucous membrane, the bladder surface by stratified epithelium. Both these tissues present a normal appearance. They do not come completely together. On one side the intestinal nucous membrane becomes thinned out, on the other layers of epithelial cells lining the bladder become gradually reduced to a single layer. It appears as if from here the epithelial cells were in the act of growing over to reach the mucous membrane, although a small strip of tissue has not yet been covered by epithelial cells. Here connective tissue lies free to the surface. This connective tissue consists of cells of an embryonal type and of fibroblasts. 'The union between the bladder and rectal walls is complete throughout their whole thickness. One generally cannot distinguish-at the line of the union-what was originally bladder and what was intestinal tissue. The mucous membrane of the rectum, and the epithelial lining of the bladder have entirely disappeared at the line of union. Still one can see the lymphoid tissue of the rectum at the site of the union, although the lymph follicles vary from the normal in that they show a diffuse infiltration of polymorphonuclear leucocytes. So numerous are the latter that they predominate over the cells of a lymphoid character.

Gram's stain shows, in the tissues of the anastomosis around the line of union, short bacilli with rounded ends, which have poorly kept the stain. These micro-organisms are probably colon bacilii. The examination of the kidney tissue-cortex, medulla and pelvis-show normal conditions, with no evidence of inflammation or degeneration.

EXPERIMENT 13.-Bitch; weight 40 pounds; operated on June 1, 1899, killed June 28, 1899. The animal is well nourished, in perfect health, very playful and lively; killed by chloroform narcosis. Excernally the abdomen presents in the median line, beginning about an inch above the symphisis pubis and extending upward for a distance of about $2 \frac{1}{2}$ inches, a healed, smooth, linear cicatrix. Upon opening the abdomen by a long median incision, the large omentum is found very slightly adherent to the internal surface of the abdominal parietes at the site of the cicatrix. The extent of these adhesions is very small. The omentum shows no signs of inflammation. 
The abdominal and pelvic cavities do not contain any fluid. The peritoneum is smooth and shining, and shows no redness or evidence of inflammation. The bladder is well contracted, firmly united to the rectum, and the place of union is everywhere covered by an uninterrupted coat of smooth peritoneum. An inspection of the intestines shows them to be normal.

The kidneys are now freed from the surrounding connective tissue, and a heated platinum loop introduced into the pelvis, and cultures made under the usual aseptic precautions. The ureters are then dissected free and the kidneys, ureters, bladder and part of the rectum removed.

The kidneys are of normal size and appearance, but, like all the internal organs, are congested in consequence of the death by chloroform. Cortex and medulla show normal relation and appearance. The pelves do not contain any appreciable amount of fluid. The mucous membrane of the pelvis is smooth and pale, and presents no signs of inflammation. The ureters are not enlarged. The internal surface of the bladder, which contained some fecal matter, is thrown into rugæ. In color it is pale pink, and mieroscopically shows no inflammatory ehanges. The anastomosis is firm, and admits the tip of the index finger. The anterior aspect of the ring is lined by bladder tissue, the posterior by rectal mucous membrane, which appears perfectly normal. Where the tissues from the bladder and the rectum meet, there is a slight depression which runs along the whote opening. The rectal mucous membrane in the neighborhood of the anastomosis appears normal. All internal organs, such as spleen, liver, lungs, heart, etc., are in a normal condition.

Mrcroscopic Examination.-Pieces of tissue were fixed in Zenker's fluid, imbedded in paraflin, and stained by various methods.

ANastomosis.-The union between the wall of the rectum and that of the bladder is perfect. There is no doubling up of either intestinal or vesical tissue, and the line of union contains very little newly-formed connective (cicatricial) tissue. No evidence of inflammation is found in the line of union. The rectum presents a normal histologic appearance. The internal surface of the bladder, however, shows some marked changes. The lining epithelium at and near the point of union is missing, and the tissue forming the surface has the character of granulation tissue. It consists of a vascular tissue formed of round cells imbedded in a matrix of fusiform cells and connective-tissue fibers. It appears, therefore, that the presence of the fecal matter with its numerous bacteria has set up an inflammatory reaction on the internal surface of the bladder. Bacteria, however, were not found in the granulation tissue, nor in the tissue forming the line of union between the bladder and rectum. The following very interesting observation was made at the line of union: In some places the columnar epithelium of the rectal mucous membrane has grown from the rectal tissue over to the bladder surface. This covering of the bladder surface by intestinal epithelium is not yet very extensive, but there undoubtedly exists a marked tendency of the intestinal epithelium to grow by extension over the bladder surface and cover it, which, in eonsequence of irritation, has lost its own epithelium. In both kidneys the pelvis, medulla and cortex present no appreciable histologic changes, and no signs of inflammation or degeneration. There are found, however, a few micro-organisms in both organs as follows:

Right kidney, in tissue near the surface of the pelvis, bacilli, $a$ few diploccoci and some deeply staining round bodies which look like either torulo saccharomyces or protozoic bodies; in the cortex a few bacilli in the convoluted tubules and in Bowman's capsules.

Left kidney, in tissue near surface of the pelvis, a few bacilli ; in the cortex likewise a few bacilli.

These micro-organisms are nowhere found in large numbers but only seen sparingly here and there.

BaCteriologic Examination.-Two glycerin-agar tubes were inoculated from the pelvis of each kidney. Of each of the two groups one developed a growth, consisting in each instance of a mixture of bacilli-colon as it appears-and diplococci.

Epicrisis: It must be conceded that both kidneys in this case had become infected. But it appears moreover that the infection must have only recently occurred. The number of micro-organisms found in the kidney was not large, and there were not yet present any appreciable histologic changes. The mucous membrane of the bladder, it appears, in consequence of the irritation from the fecal matter, had lost, in part at least, its epithelium and had developed signs of a reactionary inflammation. It is not unreasonable to suppose that the infection which had occurred might have been prevented by regularly washing out the bladder, which, in the case of a dog, cannot be well done, but which could be done with a human patient.

The above is only preliminary to a complete paper which will be published in a short time, containing a detailed account of all the experimental work, together with microphotographs, photographs of the gross specimens and drawings illustrating the technic.

\section{SEEING CAPILLARY CIRCULATION IN ONE'S OWN RETINA.*}

BY C. E. NORTON, M.D.

$$
\text { LEWISTON, ME. }
$$

This paper is presented to the Association for three reasons: 1, the subject has a scientific interest; 2 , it has a practical bearing; and 3 , I have presented it for a personal reason. I have written a short note on this subject before ${ }_{1}$. On reading this note some oculists and other scientific men have expressed the opinion that the phenomena seen are not due to the capillary circulation, but are due to muscæ volitantes. Believing, as I do, that it is possible to see the corpuscles of the blood moving in the capillaries of the retina and that these corcupsles are not the same as muscæ volitantes, nor should they receive the same name if we wish to preserve scientific accuracy in our nomenclature, I have written this paper, in which I endeavor to demonstrate the accuracy of $m y$ belief.

Over twenty years ago I discovered that while looking at a clear sky through a piece of dark blue glass I was able to see small, bright objects moving in all directions with a peculiar jerky motion. Later experiments showed me that these bright objects could be seen more plainly if several thicknesses of glass were used. I have never failed in endeavoring to demonstrate this phenomena to others. I have found that the same thing can be seen by the use of glass of other colors, but it is plainer with the blue than with any other glass that I have used. I can explain the action of colored glass only on the theory that the high color obscures the vision of external objects and allows the attention to be concentrated on entoptic phenomena and the bright color furnishes a homogeneous background which affords a proper contrast when the entoptic vision is projected on it.

I will endeavor to answer the question: "Why is this phenomenon not due to muscæ volitantes?" In the first place it will be well to define the terms used. Muscæ volitantes are due to particles, strands, or masses floating more or less freely in the vitreous humor, or in a chamber between the vitreous and the crystalline lens. Any motion of muscæ is due either to gravity or to movements of the eyes, and this movement may be in any direction. If we suddenly turn the eyes upward and immediately down again the muscæ will float upward and then gradually settle down into the lower field of vision and sometimes below the field of vision. They may follow the same path in falling down that they had in going up. Agair, by a sudden turn of the eye downward and then holding it still we may be able to cause these muscægentic particles to rebound and rise higher in the field of vision. Again, it is possible while lying on the back to get one of the particles to float directly in the center of the field of vision, and we may be able by care to balance and hold the particle in this central position.

The particles that can be seen with the blue glass have

*Presented to the Section on Ophthalmology, at the Fiftieth Annual Meeting of the American Medical Association, held at Columbus, Ohio June 6-9, 1899.

1 Annales D' Oculistique (English edition), May, 189. 